\title{
ASPECTOS HISTÓRICOS DA FOTOGRAFIA NA BAUHAUS: LINGUAGEM E MEIOS DE REPRESENTAÇÃO NOS CURSOS DE DESIGN DE PRODUTO
}

Júlio César Riccó Plácido da Silva

Universidade de São Paulo, FAUUSP

julioricco@usp.br

Cibele Haddad Taralli

Universidade de São Paulo, FAUUSP

cibeletaralli@gmail.com

Resumo: Este trabalho resgata e analisa dados históricos sobre a inserção da disciplina e oficina de fotografia na grade curricular da Bauhaus, primeira escola de design, e analisa sua influencia para o ensino, discutindo sua importância nas linguagens e como meio de representação no, e para o projeto de produto. Através de levantamentos bibliográficos e de imagens resgata as diferentes visões da fotografia aplicadas naquela escola traçando uma aproximação às linguagens fotográficas no ensino do design de produto, na atualidade, debatendo as mudanças impostas pelas tecnologias digitais, suas possibilidades para projeto de produto e para a formação de designers. Apresenta resultados parciais de pesquisa sobre a inserção da fotografia nos cursos de design nas escolas paulistas.

Palavras-chave: linguagem fotográfica; meios de representação; história da Bauhaus; design de produto

Abstract: This work recovers and analyzes historical data on the insertion of the discipline and photography workshop in the curriculum of the Bauhaus, first design school, and analyze its influence for teaching, discussing its importance in languages as well as a means of representation for product design. Through bibliographical liftings and images it rescued the different visions of the photography applied in that school tracing an approximation to the photographic languages in product design education, in the present, debating the changes imposed by the digital technologies, his means for project of product and for the designers' formation. Presents partial results of inquiry on the insertion of the photography in the design courses in the schools Paulista.

Keywords: photographic language; media representation; history of the Bauhaus; product design 


\section{INTRODUÇÃO}

Com o surgimento da fotografia no século XIX, dá-se início à época da reprodutividade visual da imagem, que foi beneficiada pelo surgimento de técnicas de produção em massa, propiciando a compreensão da diferença entre informação e expressão visual (BENJAMIN, 1985). Assim, com a popularização do invento e a cada desafio apresentado pelo uso tecnológico da ferramenta, seus desenvolvedores mobilizaram esforços contínuos na busca incessante de aperfeiçoamentos do equipamento e de todo o processo fotográfico, do registro à impressão da imagem no papel, aprimorando não apenas a ferramenta ou técnicas especializadas, mas contribuindo para a construção de uma linguagem.

O desenvolvimento da ferramenta e da linguagem deu-se gradualmente no tempo, exigindo dos profissionais mais conhecimentos a fim de manipular e transmitir mensagens, representar ideias e conceitos, além de documentar e registrar imagens passíveis de retratação. Nas últimas décadas, devido à mudança do formato fotoquímico para o eletrônico / digital, a fotografia passou a ser utilizada incessantemente como ferramenta de grande potencial, para e em todas as áreas do conhecimento, sobretudo no design de produtos.

Gomes ressalta a sua relevância como recurso adequado as várias etapas da projetação: "Potencial usado e exercitado pelos designers como ferramenta indispensável para as etapas de estudos experimentais, tendo em vista a concepção, o desenvolvimento do projeto, a documentação e o registro técnico para a fabricação, confecção ou elaboração do objeto" (GOMES, 2006, p. 214).

A imagem sempre foi um dos recursos essenciais para o processo de trabalho do designer, sendo mais e comumente utilizada, por grande parte dos profissionais, como meio de documentação e de comunicação da concepção à fase final do projeto ou do próprio produto, e com menor incidência como uma ferramenta auxiliar para o projeto. Considera-se, também, que por ser um instrumento de comunicação que utiliza mensagens visuais, a fotografia é também um discurso visual, relacionando-se, portanto, a processos criativos e artísticos. Um meio de expressão carregado de informação.

Este artigo recupera dados históricos sobre a inserção da disciplina Fotografia na grade curricular da escola de design Bauhaus, que influenciou inúmeros procedimentos de instrumentação em linguagens e representações no ensino no Brasil, e em grande parte da América do Sul, colocando ainda reflexões sobre novas possibilidades e estratégias de ensino que possam não apenas instrumentalizar o aluno dos cursos de Design para o uso da linguagem fotográfica, mas também apontar possibilidades e aplicações no processo de projeto em design.

\section{DESENVOLVIMENTO}

\subsection{Valorização da documentação do objeto}

A fotografia manteve por um bom tempo um papel simplesmente documental e de procedimento exploratório nas oficinas da Bauhaus. Em 1929, a ferramenta assumiu uma função integrativa dentro da instituição, adquirindo status de oficina em um dos departamentos (photo workshop), decorrente de reformulações da instituição ocorridas desde 1923 (Artand Technology - A new Unity). 
Isso facilitou a disseminação da estética nas atividades quotidianas, sendo incorporada na formação de uma nova cultura (SIEBENBRODT; SCHÖBE, 2012), apoiada em nova linguagem que buscava ampliar as possibilidades da alfabetização visual.

A observação da documentação de imagens desenvolvidas pelos alunos na instituição, retratadas em bibliografia, apresenta-se com diversas influências estéticas e experimentais, dado o grau de possibilidades e conceitos possíveis com o uso da ferramenta, o que permitiu explorar a criatividade nas abordagens pedagógicas apoiadas pela instituição (SIEBENBRODT; SCHÖBE, 2012).

Fica evidente nas publicações realizadas pela instituição que, na época, o uso da ferramenta variou em retratos, documentação de trabalhos, composição de e do objeto, arquitetura, fotografia de produto (figura 1), utilização nas etapas do projeto, natureza morta (figura 2), fotografia de ambientes e o uso da imagem para montagens e foto colagens (figuras 3 e 4).As subseções são numeradas em algarismos arábicos.

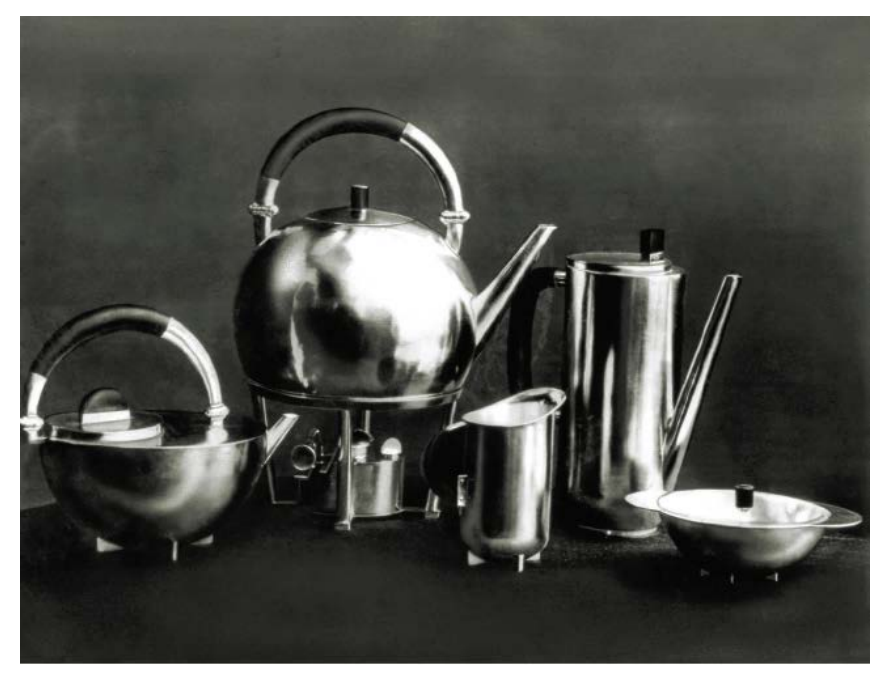

Figura 1 - Lucia Moholy, "Silver coffee and tea service with alcohol-fuelled warmer by Marianne Brandt, 1924".

Fonte: Siebenbrodt; Schöbe, (2012, p. 207).

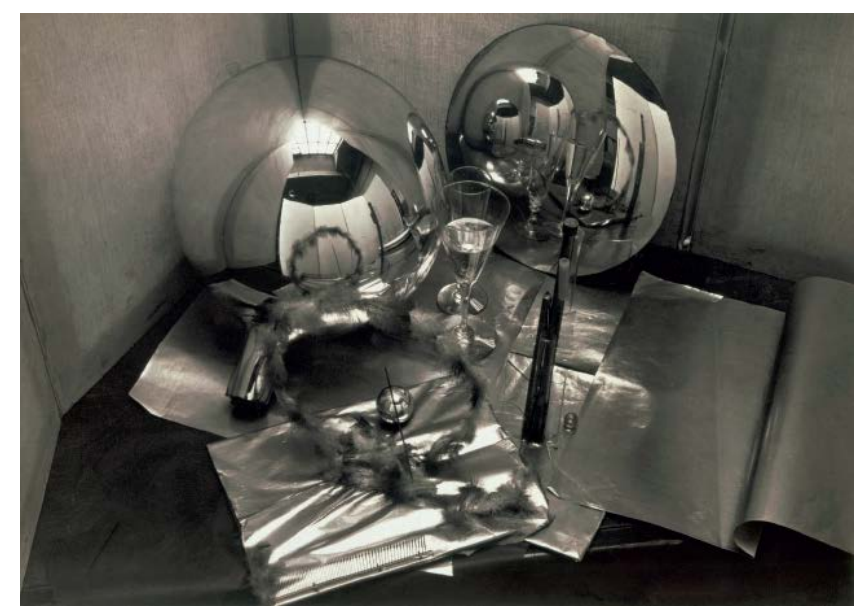

Figura 2 - Georg Muche, "Still Life in Glass, 1921/22".

Fonte: Siebenbrodt; Schöbe, (2012, p. 206). 

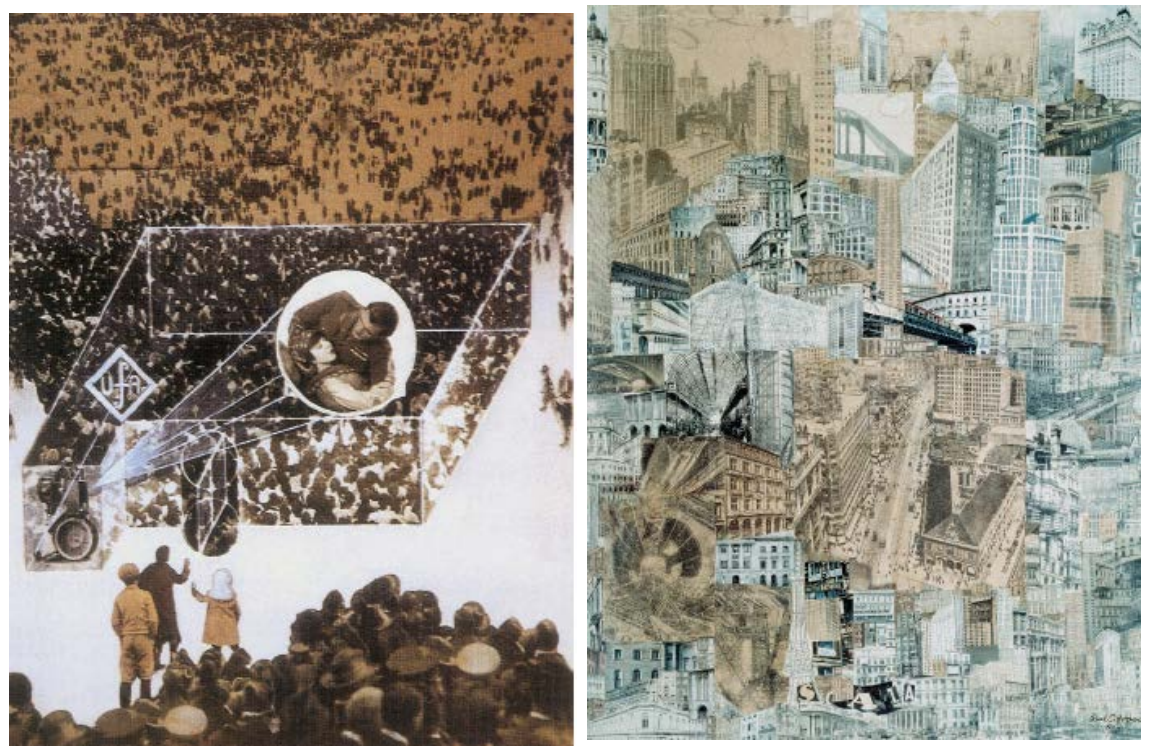

Figura 3 - à esquerda, Paul Citroen, "Big City (Metropolis), 1923”.

Fonte: Siebenbrodt; Schöbe, (2012, p. 209).

Figura 4 - à direita, László Moholy-Nagy, “Photoplastic, 1925”.

Fonte: Siebenbrodt; Schöbe, (2012, p. 209).

Durante os anos de 1919 a 1923 (SIEBENBRODT; SCHÖBE, 2012) observa-se que a produção fotográfica foi predominantemente o de documentação de produtos ou do resultado de trabalhos dos discentes (incluindo modelos e protótipos), desenvolvidos durante as disciplinas, provavelmente incentivado pelo professores.

A fotografia atendia ao objetivo da documentação para fins de registro, arquivamento e publicidade da instituição, além de sua inserção em livros, conferências e revistas da instituição (SIEBENBRODT; SCHÖBE, 2012), distanciando-se do uso e aplicação como gênero de uma linguagem conceitual, autônoma ou de intenção artística ou criativa. Nesta fase inicial, o uso da ferramenta aparece subjugado ao valor fotográfico dos objetos (isto é, da produção discente e docente).

Diferente e além do valor de uso, o caráter linguístico da fotografia faz dela uma das atividades com alto grau de originalidade, determinando-se pela sua aplicação, assim como o uso particular da língua pode determinar o significado ou o valor de um termo ou expressão dentro de um idioma (VIANNA; CAMPOS, 2011).

Enquanto representação, os valores fotográficos aparecem dedicados a aspectos das aplicações práticas da ferramenta, ou seja, a fotografia teve um papel de registro das atribuições funcionais dos objetos (idealizados, projetados) em cada fase do projeto.

Walter Gropius, fundador e diretor da instituição, propôs essa compreensão do uso da fotografia, quando colocava que a fotografia destinava-se a ser um instrumento de reprodução neutra da realidade, a fim de transmitir uma informação objetiva (SIEBENBRODT; SCHÖBE, 2012), reduzindo assim outras possibilidades, de caráter experimental e exploratório. Erich Consemüller e Lucia Moholy desenvolveram neste contexto grande parte da documentação de todas as áreas de atuação da Bauhaus, resultando no registro generoso e amplo dos trabalhos desenvolvidos, colaborando para a ampliação dos arquivos históricos da instituição. 
Do ponto de vista de Siebenbrodt e Schöbe (2012), esta visão foi preponderante até o ano de 1927 , onde os produtos gerados e produzidos eram registrados em conjunto ou classificados por sua lógica de funcionamento, manifestando expressão fiel aos conceitos modernistas, que caracterizaram o pensamento e a proposta da instituição, sem abertura para a construção de outras narrativas.

A proposta de László Moholy-Nagy autodidata (entre 1923 a 1925, em Weimar, e de 1925 a 1928, em Dessau) trouxe outra vivência com a impressão de um caráter exploratório à fotografia, proporcionando experiências visuais sem precedentes (FONTCUBERTA; COSTA, 1988). Decididamente, essa nova perspectiva influenciou no desenvolvimento desta ferramenta na instituição, contribuindo para que o campo ganhasse importância como um meio independente de expressão. Respaldadas por suas colocações conceituais denominadas "Nova Visão" e "Nova Objetividade", observam-se duas tendências incorporadas a partir da expressão "Nova Fotografia", idealizadas por ele e por Walter Peterhans (SIEBENBRODT; SCHÖBE, 2012), uma com foco no objeto a ser retratado; a outra, como elemento fotográfico criativo em oposição à documentação.

Deste modo, Moholy-Nagy desde 1923, influenciou decisivamente o desenvolvimento da fotografia na Bauhaus, introduzindo objetivos voltados para a experimentação de imagens no âmbito da percepção, colaborando para a constituição de conhecimentos e habilidades. Além disso, o docente apoiou o uso da ferramenta no curso preparatório e nas oficinas de metal.

Grande parte dessas ideias e do desenvolvimento experimental da fotografia, na instituição, entre 1927 e 1928, foi adotado posteriormente em outros campos, como a publicidade e o marketing. Com a saída de Moholy-Nagy, estes ensinamentos e práticas foram reduzidos (SIEBENBRODT; SCHÖBE, 2012), embora já tivessem influenciado os campos do design, das artes visuais, do marketing e da publicidade. No ano de 1929, Walter Peterhans é nomeado chefe da oficina de fotografia (SIEBENBRODT; SCHÖBE, 2012).

Fica evidente a preocupação dos precursores, Moholy-Nagy e Peterhans, em reconhecer a importância de desenvolver nos alunos habilidades e competências para que pudessem usufruir melhor dos recursos experimentais da ferramenta e exercer melhor as funções técnicas da linguagem fotográfica.

\subsection{O fascínio pela composição da luz}

O processo fotográfico tem a ver com o ato de descoberta imediata dos efeitos gerados pela luz. Nesse aspecto, na Bauhaus, foram desenvolvidas diversas incursões dentro dos temas das esculturas e objetos tridimensionais direcionadas à relação da luz sobre o movimento. Estes experimentos, em práticas simuladas, ampliaram o repertório dos alunos sobre os efeitos gerados pela luz (possivelmente trabalhadas em escala reduzida).

Uma dessas criações foi desenvolvida por Moholy-Nagy, que era fascinado pela luz, através do modulador de luz no espaço (Título Original - Licht-Raum Modulator 1922-30 - figura 5). 


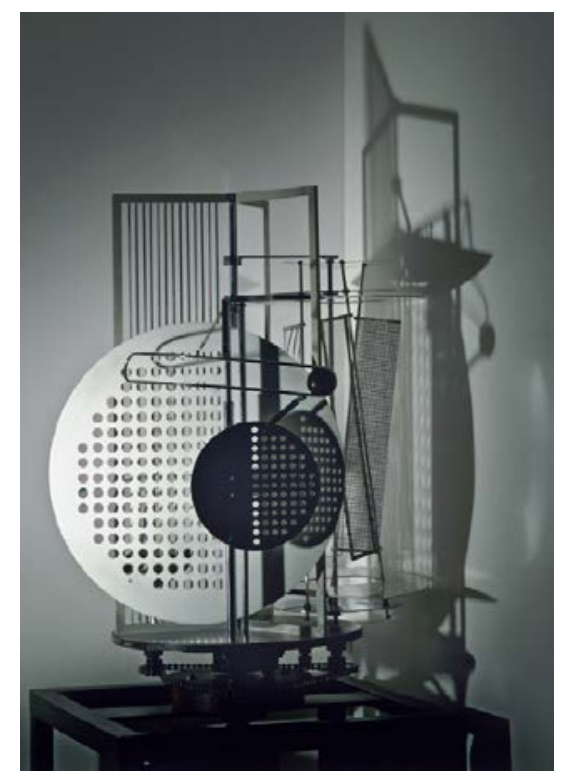

Figura 5 - Light-Space Modulator, Réplica 1970.

Fonte: Bauhaus-Archiv, (2009, p. 275).

Trata-se de uma escultura cinética desenvolvida a partir de três estruturas metálicas móveis, arranjadas sobre um disco rotatório, que formam o núcleo do modulador, desenvolvido para demonstrar o jogo de luz como manifestação do movimento. Propunha explorar o desenho da luz atrelada ao movimento, através de um aparato que incorporava mudanças na iluminação, gerando múltiplos efeitos óticos.

Outra criação foi idealizada por Edmund Collein, em 1928, na oficina de escultura da Bauhaus de Dessau, disciplina ministrada pelo docente Joost Schmidt (Sculpting Workshop - de 1925 a 1930), uma máquina (figura 06) que permitia uma série de experiências, a partir de figuras, planos, linhas e movimentos articulados entre si, resultando em inúmeras formas que se interpenetravam. Esta criação foi gerada a partir de um exercício para investigar o uso de formas planimétricas e estereométricas e a relação entre corpo e espaço positivo e negativo em relação à luz e sombra, visualizada por meio da projeção de luzes e da rotação e torção, em movimento real e virtual (BAUHAUS-ARCHIV, 2009).
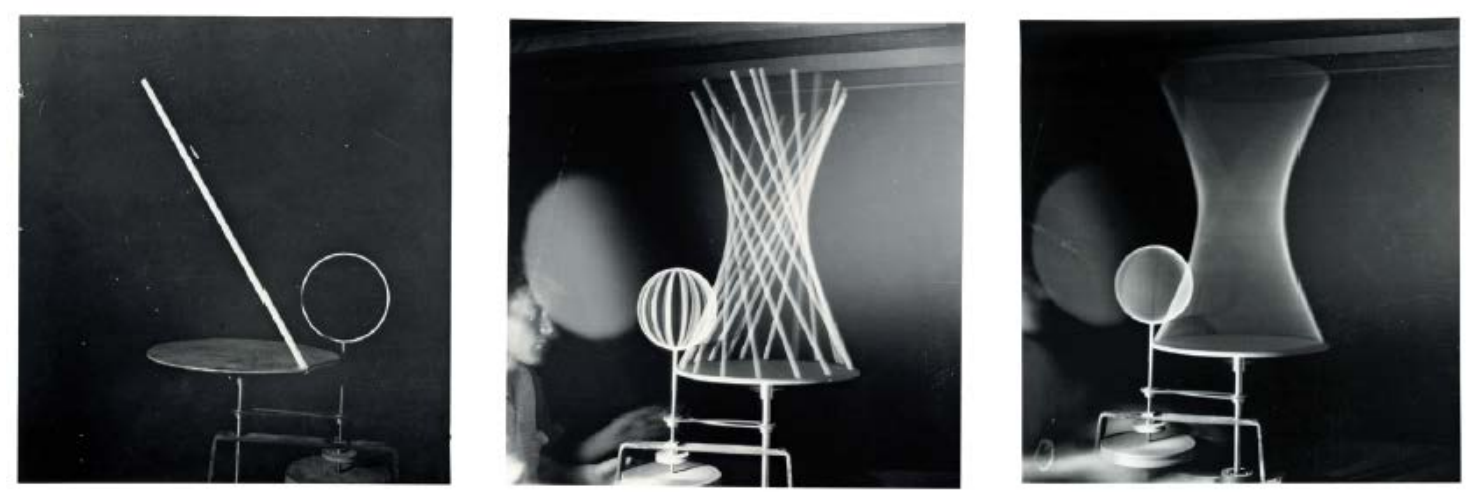

Figura 6 - Série de experimentos: "Von Grader und Kreis zu Hiperbolóide und Kugel”, para a aula de Joost Schmidt na oficina de escultura.

Fonte: Bauhaus-Archiv, (2009, p. 279). 
Os estudos direcionados à composição da luz e de interpenetração tinham a intenção de ampliar e desenvolver as qualidades da imaginação espacial, a experiência da percepção sensorial do espaço e a consciência visual de planos de interseção de volumes negativos, com vistas à construção e produção complexa da forma.

\subsection{A oficina de fotografia na Bauhaus}

A Bauhaus não foi pioneira na inserção da fotografia no campo, sendo que Siebenbrodt e Schöbe (2012) esclarecem que a disciplina básica compreendia objetivamente a fotografia de produto de forma refinada com detalhes ricos em retratos superficiais e nuances de sombras mínimas no retrato bidimensional e também em objetos com grandes volumes.

Como já mencionado, o ano de 1929 é considerado como o ano da ruptura definitiva (figura 7) com o histórico do desenvolvimento da fotografia na instituição, onde foi instituída como uma oficina paralela ao curso, fase que foi caracterizada, principalmente, pelo trabalho do fotógrafo Walter Peterhans (SIEBENBRODT; SCHÖBE, 2012). Peterhans desenvolveu suas atividades como docente de fotografia nos anos de 1929 a 1932, na Bauhaus de Dessau, e de 1932 a 1933, na Bauhaus de Berlim.

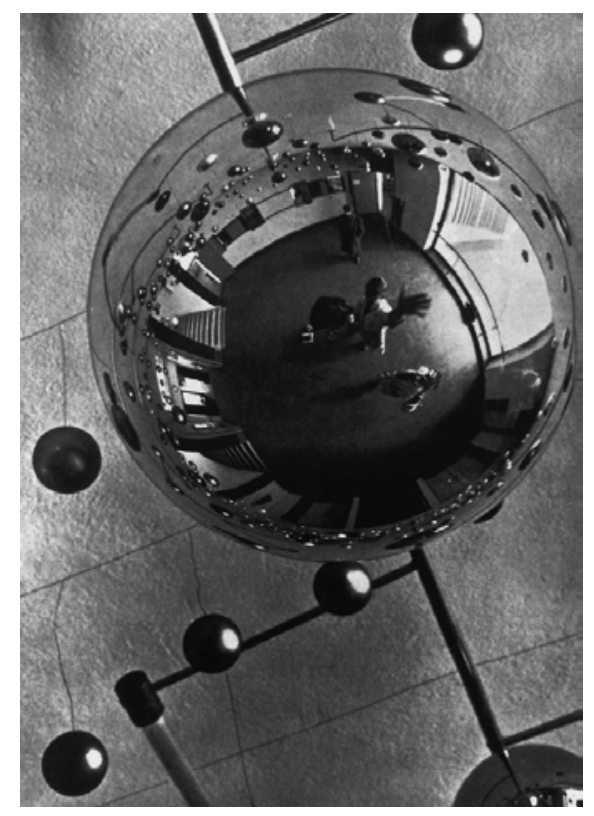

Figura 07 - Walter Funkat, “Glass spheres”, 1929.

Fonte: Siebenbrodt; Schöbe, (2012, p. 206).

Todavia, descontentamentos em relação à baixa carga horária das oficinas, tornaram-se obstáculos para o aprofundamento dos conhecimentos teóricos necessários. Percebeu-se, assim, foi identificada a necessidade da criação de uma disciplina específica no curso de design, para ampliar o horizonte perceptivo do estudante.

No ano de 1930, a fotografia mostrou-se autônoma no currículo, enquanto que em 1931 tornou-se um curso anual, sendo requisito necessário para a graduação em Design (SIEBENBRODT; SCHÖBE, 2012). A instituição investiu em equipamentos destinados à formação especializada e técnica, que incluíam um quarto escuro com ampliadores, uma série de projetores e instrumentos óticos (não relacionados e detalhados na literatura). 
Mesmo com a inserção da oficina de fotografia como disciplina autônoma no currículo da Bauhaus e investimentos para sua formação, fica evidente, através do resgate histórico apresentado, sua subutilização no design de produto, além da contribuição ao avanço nas artes visuais com usos exploratórios realizados pelos docentes Moholy-Nagy e Peterhans, que conforme mencionado anteriormente, em um curto período de tempo, dentro da instituição, influenciaram gradativamente novas possibilidades para o campo do marketing, da publicidade e do design gráfico.

A ferramenta ficou disponível para todos os cursos, mas sua instrumentação e uso foram diluídos nas disciplinas, e explorados por docentes e técnicos que tiveram experiências anteriores na técnica e no dispositivo, influenciando as artes visuais. Assim, fica claro que com a saída dos docentes houve a retomada e manutenção do uso da imagem apenas como representação visual, clara, direta e documental dos objetos, atendendo aos campos da publicidade, do marketing e do design gráfico, relegando os avanços destinados ao campo do design de produto.

\subsection{A Linguagem fotográfica e a formaçao em design de produto}

Nos cursos de design brasileiros a inserção da fotografia variou de acordo com as possibilidades de recursos e investimentos em infraestrutura, como a montagem e a operação de oficinas fotográficas e/ou de mídias visuais, ou a previsão de uso em disciplinas (ou mesmo em parte delas) dedicadas a documentar processo de projeto, modelos de estudo, avaliações formais de objetos, entre outras estratégias didáticas para a formação em design.

As mudanças e avanços tecnológicos nos dispositivos e programas para fotografia digitais, colocam a disposição hoje recursos imediatos de captura de imagem e movimento, em mídias comuns e bem disseminadas na sociedade (como o celular e tablet), mas com outra qualidade quando comparado a processos fotográficos de equipamentos e programas, e outros, correlatos como o escaneamento, a termografia, que demandam investimentos próprios e também das instituições de ensino.

Assim cabe realizar pesquisas sobre como as novas estruturas curriculares atuais, influenciadas pela experiência didáticas e recursos da Bauhaus, foram modificando e estruturando currículos das escolas de design, fase aos avanços tecnológicos dessa ferramenta; e como a política de ensino superior do País lida com essas mudanças, com gestão estratégica, investimentos empresariais para o atendimento a novos segmentos de mercado ou se os cursos livres atendem às demandas mercadológicas com qualidade. E também como este conjunto de ações influencia e se rebate no docente, como mediador dos processos de formação em design.

Os docentes ligados à disciplina de fotografia podem e incentivam o uso das ferramentas com o intuito de ultrapassar o formato tradicional da representação do projeto no papel e a do volume (e ocupação do espaço tridimensional) dos objetos, buscando enfatizar novos conceitos de espaço. Para o designer, a linguagem fotográfica pode constituir ferramenta no processo de desenvolvimento de produto, possibilitando identificar e descrever as diferentes redes e construções discursivas de representações da imagem e da função e forma do próprio que o objeto engendra para sua concepção. 
É importante frisar, citando Escorel (2005), que as inúmeras e incessantes possibilidades de renovar as tecnologias disponíveis para a reprodução, assim como quase infinita é a gama de materiais em que o profissional poderá imprimir (ou fabricar) suas decisões de projeto, todavia a essência eminentemente uniforme e homogênea da linguagem do design de produto não se altera, sobressaindo-se sobre o uso das ferramentas.

\subsection{Influências e inserção da fotografia nos cursos de Design no Brasil}

Segundo Couto (2008), a estrutura dos cursos de Design no Brasil teve origem na Bauhaus. Estrutura que influenciou grande parte da constituição das disciplinas de fotografia, alicerçadas em conceitos ligados e direcionados ao campo do marketing e da publicidade, conforme identificado na literatura Bauhaus-Archiv (2009) e Siebenbrodt; Schöbe, (2012).

Assim, não percebemos hoje um afastamento da proposta original, mas sim um distanciamento do conhecimento aplicado durante poucos anos na instituição, ministrados por dois grandes precursores - Moholy-Nagy e Walter Peterhans.

Verifica-se na analise de planos de disciplinas, e de oferta de infraestrutura institucional na maioria dos cursos de design paulistas em operação ${ }^{1}$ que, mesmo referenciados na adoção de conceitos formativos e expressivos da Bauhaus isto não tem contribuído para que a fotografia ofereça ao aluno uma ferramenta valida e essencial como meio de expressão voltada ao design de produto, incentivando-o a uma ação ativa incorporada aos procedimentos de projetos, isto é instrumentando os discentes a reconhecer na imagem fotográfica uma atividade projetual; uma forma de controle e domínio da linguagem conduzida e manipulada conforme a necessidade de uso.

Marinho et al. (2014) enfatiza que o conhecimento da linguagem possibilita um reconhecimento dos instrumentais de representação do projeto, que o designer emprega para construir um pensamento, ou concepção hoje tarefa complexa dada a velocidade das descobertas, dos avanços e substituições de tecnologias, processos, e técnicas aplicadas aos dispositivos e ferramentais digitais.

Além da disponibilidade e do acesso da tecnologia, os conteúdos didáticos da fotografia migraram para outras disciplinas, e da mesma forma, cursos, oficinas ou workshops de fotografia absorveram novos conhecimentos. O fato é que ela serve como uma ferramenta de apoio para outras disciplinas, exigindo dos docentes o domínio deste conhecimento e a necessidade de instrumentar os alunos para estas mudanças e possibilidades estimulando a reflexão.

Seu exercício vem agregando diversos saberes oriundos de outras áreas da atividade criativa, influenciando-as e sendo por elas, crescentemente, influenciadas (VIANNA; CAMPOS, 2011), principalmente devido aos softwares que possibilitam a integração de técnicas de linguagens tanto da fotográfica como do design para um processo relacional e integrativo.

Se projetistas entenderem que o processo de criação é um avanço progressivo sobre uma cadeia de variáveis, e se aceitarmos que a especialidade da linguagem

\footnotetext{
Esta pesquisa integra investigações da tese de Doutorado em andamento na Faculdade de Arquitetura e Urbanismo da Universidade de São Paulo - FAU-USP, sobre Linguagem fotográfica e Representação em Design de Produtos, liderada pela orientadora Prof ${ }^{a}$. Dr ${ }^{a}$. Cibele Haddad Taralli e o autor deste artigo.
} 
fotográfica vai além da fotografia realista (FONTCUBERTA E COSTA, 1988) ou pura representação, a fotografia possibilitará múltiplas funções comunicativas, limitando-se apenas à opção individual de cada fotógrafo em realizar o registro.

Segundo dados oficiais do Ministério da Educação e Cultura (MEC), no Estado de São Paulo ${ }^{2}$ estão cadastradas treze instituições de ensino de Design de Produto (tabela 1).

Tabela 1 - Instituições de Ensino do Estado de São Paulo de Design de Produto.

\begin{tabular}{|c|c|c|}
\hline INSTITUIÇŌES - Nome da IES Sigla & GRADUAÇẮO & DISCIPLINA \\
\hline (417) UNIVERSIDADE CIDADE DE SĀO PAULO - UNICID & a graduaçăo năo abriu novas turmas & \\
\hline (496) UNIVERSIDADE DE FRANCA - UNIFRAN & a graduaçăo năo abriu novas turmas & \\
\hline (420) UNIVERSIDADE DE MARILIA - UNIMAR & não tem gradução de design de produto & \\
\hline (150) UNIVERSIDADE DE SOROCABA - UNISO & năo tem graduaç̧̃o de design de produto & \\
\hline (271) UNIVERSIDADE DO OESTE PAULISTA - UNOESTE & a graduaçăo năo abriu novas turmas & \\
\hline (56) UNIVERSIDADE ESTADUAL PAULISTA JÚLIO DE MESQUITA FILHO - UNESP & Graduaçăo em Design de Produto & Fotografia $1-2^{\circ}$ semestre \\
\hline (316) UNIVERSIDADE NOVE DE JULHO - UNINOVE & sem informaçōes no site e pelo telefone & \\
\hline (162) CENTRO UNIVERSITARIO BELAS ARTES DE SĀO PAULO - FEBASP & Graduaçăo em Design de Produto & Linguagem fotográfica $-3^{\circ}$ semestre \\
\hline (11807) FACULDADE DE TECNOLOGIA DO ISTITUTO EUROPEO DI DESIGN - IED S & |f Graduação em Design de Produto & Fotografia -1 - semestre \\
\hline (16934) Faculdade Melies de Tecnologia - Melies & não tem graduaçăo de design de produto & \\
\hline (3990) FACULDADE SĀO BERNARDO DE TECNOLOGIA - Anhanguera & Graduação em Design de Produto & Fotografia Básica $-1^{*}$ semestre e Imagem digital 2" semestre \\
\hline (2556) FIAM-FAAM - CENTRO UNIVERSITARIO - UNIFIAM-FAAM & não consta a graduaçăo de design de produto & \\
\hline (466) UNIVERSIDADE ANHEMBI MORUMBI - UAM & não consta a graduação de design de produto & \\
\hline
\end{tabular}

Fonte: "Elaborado pelo autor, com base em pesquisa realizada na Lista das Instituições de Educação Superior e Cursos Cadastrados no sistema e-MEC". Disponível em: <http://emec.mec.gov.br/>. Acesso em: 2 de abr. de 2016.

Através destes dados é possível identificar que apenas quatro instituições mantêm na graduação em design de produto disciplinas de fotografia, sendo que são distribuídas de formas diferentes durante os semestres, sendo que apenas uma instituição mantém na grade curricular duas disciplinas voltadas ao uso da ferramenta e linguagem.

Porém, acredita-se com tais evidências que o principal problema gerador da retirada ou redução da carga horária das disciplinas voltadas ao ensino da fotografia nos cursos de Design no Brasil foi, e está relacionado a falta de recursos e investimentos nas mudanças sucessivas e frequentes de tecnologia; aliado a um quadro de evasão significativa de alunos no curso, gerando a necessidade da busca de cursos fora da instituição.

Deste modo, as disciplinas voltadas à linguagem fotográfica devem estar sintonizadas com as mutações do campo profissional, priorizando modernas plataformas tecnológicas e investimentos permanentes. Existe a necessidade de adequada estruturação dos laboratórios e da constante atualização do ferramental e de docentes com domínio das novas tecnologias.

\section{CONSIDERAÇÕES FINAIS}

A imagem sempre foi um dos recursos fundamentais para o processo de trabalho do designer, sendo utilizado por grande parte dos profissionais de forma artística e documental e não como uma ferramenta auxiliar para o processo de projeto. Considera-se, que o domínio dos dispositivos, da técnica, dos conceitos embarcados, das possibilidades e recursos em prol da imagem pela fotografia, tem potencial para constituir um aliado expressivo no desenvolvimento de projetos, além do uso instrumental mais usual no campo do design de produto. Nos dados em

2 Lista das Instituições de Educação Superior e Cursos Cadastrados no sistema e-MEC, dado oficial embora cientes de que trás alguma inconsistência nos dados. Disponível em: <http://emec.mec.gov.br/>. Acesso em: 2 de abr. de 2016. 
investigação (pesquisa em andamento) nota-se a falta de priorização e incentivo ao uso por grande parte da academia.

Possibilidades atuais no processamento computacional (software e hardware) em conjunto com a digitalização das imagens, geram possibilidades para a concepção, a manipulação, e a aferição fotográfica. É necessário assim validar o uso da ferramenta para o campo do design de produto, a partir dos processos educativos e de formação do designer.

Durante o desenvolvimento deste trabalho, ficou evidente que a passagem da tecnologia analógica para a digital afetou a colocação da fotografia como conhecimento e técnicas nas disciplinas nas instituições de ensino em design, sendo que dentre as diversas variáveis influentes nesse processo, pode-se citar os ciclos de substituição de tecnologias em descompasso com os avanços tecnológicos, fazendo com que os alunos busquem uma atualização fora da instituição.

É notório que a linguagem fotográfica potencializa o desenvolvimento de habilidades próprias da linguagem, todavia, a carga horária destinada ao ensino da fotografia e de suas habilidades é muito inferior se comparada a outras disciplinas. Outro ponto relevante é que grande parte desses avanços estão direcionando a atenção para o ato pós-fotográfico, devido à utilização de softwares de tratamento, relegando e esquecendo os fundamentos técnicos do processo pré-fotográfico de linguagem.

Identifica-se, portanto, uma necessidade de mudanças pedagógicas na formação, nas práticas didáticas, no uso de técnicas e na ampliação das disciplinas de meios e representação, com foco na linguagem fotográfica, acompanhando os avanços tecnológicos e suas variáveis de aplicação dentro do campo.

\section{REFERÊNCIAS}

BAUHAUS-ARCHIV, Museum fürGestaltung, Stiftung Bauhaus Dessau, KlassikStiftung Weimar, Museum of Modern Art (New York, N.Y.), and Martin-Gropius-Bau (Berlin, Germany). Bauhaus: a conceptual model. (Ostfildern: HatjeCantz), 2009.

BENJAMIN, W. Pequena História da Fotografia. In: Obras Escolhidas, v. 1. São Paulo: Brasiliense, 1985.

COUTO, R. M. S. Escritos sobre o ensino de design no Brasil. Rio de Janeiro: Rio Book's, 2008.

ESCOREL, A. L. As Linguagens do design. In: LIMA, G. C. Design: Objetivos e perspectivas. Rio de Janeiro: PPDESDI UERJ, 2005.

FONTCUBERTA, J.; Costa, J. Foto-diseño. México: Ed. CEAC, p.260, 1988.

GOMES, J. F. Design do objeto: bases conceituais. São Paulo: Escrituras, 2006.

MARINHO, C.; BRASIL, A.; CARDOSO, D. 2014. Estratégias de ensino do design a partir de uma abordagem processual do projeto: as contribuições da crítica de processo nas investigações sobre método de projeto. In: COUTINHO, Solange G.; MOURA, Monica;

CAMPELLO, Silvio Barreto; CADENA, Renata A.; ALMEIDA, Swanne (orgs.). Proceedings of the 6th Information Design International Conference, 5th InfoDesign, 6th CONGIC [Blucher Design Proceedings, num.2, vol.1]. São Paulo: Blucher, 2014. ISSN 2318-6968, ISBN 978-85-212-0824-2. 
SIEBENBRODT, M.; SCHÖBE, L. Bauhaus. Parkstone international, 2012.

VIANNA, W.; CAMPOS, J. L. Fotografia, linguagem, design: uma rápida digressão. Agitprop (São Paulo), Ano IV, nº. 38, 2011. 